\title{
Ambulatory Care Facility
}

National Cancer Institute

\section{Source}

National Cancer Institute. Ambulatory Care Facility. NCI Thesaurus. Code C16281.

A medical care center that provides healthcare services on an outpatient basis. 